\title{
Acúmulo e efeitos fitotóxicos do flúor em folhas de boldo-gambá e capim-cidreira utilizadas para chás
}

\author{
Naiara Viana Campos ${ }^{(1)}$, Aristéa Alves Azevedo( ${ }^{(1)}$ e Bruno Francisco Sant'Anna-Santos ${ }^{(2)}$
}

\begin{abstract}
(1)Universidade Federal de Viçosa, Programa de Pós-graduação em Botânica, Departamento de Biologia Vegetal, Avenida PH Rolfs, s/no, CEP 36570-000 Viçosa, MG. E-mail: tianay_bio@yahoo.com.br, aazevedo@ufv.br (2)Universidade Federal de Minas Gerais, Instituto de Ciências Agrárias, Avenida Universitária, no 1.000, Caixa Postal 135, Bairro Universitário, CEP 39404-006 Montes Claros, MG. E-mail: brunoufmg@ufmg.br
\end{abstract}

Resumo - O objetivo deste trabalho foi avaliar o potencial de acúmulo de fluoreto em folhas de boldo-gambá (Plectranthus neochilus) e capim-cidreira (Cymbopogon citratus), determinar o percentual de liberação do poluente por meio da infusão e caracterizar, visual e microscopicamente, os danos foliares causados pelo poluente. Mudas das duas espécies foram submetidas a nevoeiro simulado com fluoreto de potássio. $\mathrm{O}$ acúmulo de fluoreto na matéria seca foi mensurado com eletrodo específico em folhas lavadas e não lavadas, infundidas e não infundidas. O percentual de flúor disponibilizado nos chás foi superior para capim-cidreira, embora essa espécie apresente acúmulo de flúor menor que o boldo-gambá. Não foram observados sintomas visuais nas folhas das espécies estudadas, mas ao microscópio eletrônico de varredura, constatou-se a alteração da turgidez das células epidérmicas, ruptura da cutícula e deformação de estômatos e tricomas. O elevado teor de fluoreto nas folhas de C. citratus e P. neochilus e a ausência de sintomas visuais evidenciam que as espécies são tolerantes ao poluente. A lavagem das folhas em água é ineficiente para a remoção do flúor. O acúmulo e a liberação diferenciais de flúor estão relacionados às características morfoanatômicas das espécies analisadas.

Termos para indexação: Cymbopogon citratus, Plectranthus neochilus, alterações estruturais, anatomia foliar, micromorfologia, plantas medicinais.

\section{Fluorine accumulation and its phytotoxic effects in blue coleus and lemongrass leaves used for tea}

\begin{abstract}
The objective of this work was to evaluate the fluoride accumulation in leaves of blue coleus (Plectranthus neochilus) and lemongrass (Cymbopogon citratus), the percentage of fluoride released through infusion and to characterize visually and through microscopy the injuries caused by the pollutant. Saplings of the species were subjected to a simulated fog with potassium fluoride. Fluoride accumulation in dry matter was measured by a specific electrode in washed and unwashed leaves, subjected and not subjected to infusion. The percentage of available fluorine in teas was higher for lemongrass leaves, even though this species shows a lower fluorine accumulation than blue coleus. No visible symptoms were observed in leaves of either species, although changes in turgidity of the epidermal cells, cuticle rupture and trichome and stomata deformation were observed through scanning electron microscopy. The high contents of fluoride in leaves of C. citratus and $P$. neochilus and the absence of visual toxicity symptoms reveal that these species are tolerant to the pollutant. Washing the leaves in water is inefficient to remove fluoride. Differences in accumulation and release of fluorine are related to the morpho-anatomical characteristics of the species studied.
\end{abstract}

Index terms: Cymbopogon citratus, Plectranthus neochilus, structural alterations, foliar anatomy, micromorphology, medicinal plants.

\section{Introdução}

A utilização de plantas medicinais é uma das formas mais antigas empregadas para o tratamento de enfermidades, graças às propriedades curativas de substâncias presentes em determinadas espécies. Apesar de inúmeros benefícios oferecidos pelos fitoterápicos, o uso indiscriminado pode causar sérios problemas à saúde, decorrentes de princípios tóxicos encontrados nas plantas (Martins et al., 2000) e da contaminação das plantas por patógenos ou poluentes (Wong et al., 2003; Zaroni et al., 2004).

Nas proximidades de áreas industriais, a vegetação está constantemente exposta a elevados níveis de poluentes gasosos e particulados que podem ser depositados na superfície das folhas e acumulados nos tecidos vegetais (Klumpp et al., 1998). Entre os poluentes atmosféricos, o flúor é o mais fitotóxico, e as

Pesq. agropec. bras., Brasília, v.45, n.7, p.646-653, jul. 2010 
fundições de alumínio, as fábricas de vidros, cerâmicas e adubos minerais são os principais responsáveis pelo aumento da concentração de flúor na atmosfera (Weinstein \& Davison, 2004).

A exposição ao flúor pode induzir efeitos tóxicos não só nas plantas, mas também nos animais (Weinstein \& Davison, 2004). A entrada de fluoretos no corpo humano se dá por ingestão, inalação e, em casos extremos de exposição aguda, pela pele. Os compostos de flúor, dependendo da concentração, possuem efeitos desejáveis ou tóxicos ao organismo humano.

A ingestão de uma pequena quantidade diária de flúor é considerada benéfica na prevenção de cáries, e a concentração ótima situa-se entre 2,0-4,0 $\mathrm{mg} \mathrm{dia}^{-1}$ para crianças e adultos (World Health Organization, 2002). No entanto, o consumo de elevadas doses de fluoretos pode acarretar efeitos prejudiciais no esmalte dentário, fluoroses nos ossos (Cao et al., 2003; Harinarayan et al., 2006) e alterações em órgãos como fígado e rins (Xiong et al., 2007).

Os líquidos representam a maior fonte de ingestão de fluoretos, e os chás constituem um bom exemplo dessa condição, já que o flúor acumulado nas folhas é liberado durante a infusão (World Health Organization, 2002). O uso frequente de plantas medicinais para o preparo de chás pode constituir um risco para a saúde humana em locais sujeitos à poluição por flúor. O consumo habitual de chás, em regiões onde a água apresenta elevada concentração de flúor, ocasionou fluoroses em consumidores de diversos países como China, Tibete e Turquia (Yi \& Cao, 2008). No entanto, pesquisas relacionadas aos riscos da ingestão de flúor em decorrência da presença do poluente na atmosfera são escassas.

Entre as espécies mais citadas em levantamentos sobre a utilização de plantas medicinais no Brasil destacam-se o boldo-gambá (Plectranthus neochilus Schltr.) e o capim-cidreira [Cymbopogon citratus (DC.) Stapf] (Pilla et al., 2006; Taufner et al., 2006; Lima et al., 2007).

Cymbopogon citratus, popularmente conhecida como capim-limão, erva-cidreira ou capim-santo, é originária da Índia e desenvolve-se em todo o Brasil. Seu chá é muito apreciado e utilizado como calmante, anticonvulsionante, antiespamódico e analgésico (Lorenzi \& Matos, 2002). Originário da África, o boldo-gambá é uma erva perene, com ramos semissuculentos prostrados sobre o solo e também eretos. Sua infusão é um tônico amargo utilizado no tratamento de males de fígado e problemas de digestão (Duarte \& Lopes, 2007).

O objetivo deste trabalho foi avaliar o potencial de acúmulo de fluoreto em folhas de boldo-gambá e capim-cidreira, determinar o percentual de liberação do poluente por meio de infusão e caracterizar, visual e microscopicamente, danos foliares causados pelo poluente.

\section{Material e Métodos}

Foram realizados dois experimentos, em abril-maio e em dezembro de 2008, na Unidade de Crescimento de Plantas da Universidade Federal de Viçosa (UFV, MG), utilizando-se as espécies herbáceas $C$. citratus (Poaceae) e P. neochilus (Lamiaceae).

Mudas obtidas por propagação vegetativa de um mesmo indivíduo de cada espécie foram plantadas em vasos de plástico, com capacidade para $0,65 \mathrm{~kg}$, contendo uma mistura de solo, areia e adubo orgânico numa proporção de $3: 1: 1$. As mudas eram provenientes do Grupo Entre-Folhas, da UFV, e receberam solução nutritiva de Hoagland (Hoagland \& Arnon, 1950) uma vez por semana.

Ao atingir três meses de idade, as plantas foram submetidas a 15 min diários de nevoeiro simulado de 3,92 $\mathrm{mm} \mathrm{dia}^{-1}$, com solução de fluoreto de potássio (KF) contendo $10 \mu \mathrm{g} \mathrm{mL}^{-1}$, no primeiro experimento, e $20 \mu \mathrm{g} \mathrm{mL}^{-1}$, no segundo. O nevoeiro, aplicado em câmara de simulação construída com adaptações a partir do modelo de Evans et al. (1977), teve duração de 20 dias, no primeiro experimento, e 10 dias no segundo. As plantas do tratamento controle foram submetidas ao nevoeiro simulado utilizando-se apenas água deionizada. Foi utilizado o delineamento experimental inteiramente casualizado com cinco repetições por tratamento (controle e flúor), no primeiro experimento, e seis no segundo. Ao término da simulação, foi feita a coleta de amostras foliares para análises microscópicas e de folhas inteiras para o preparo de chás e para a quantificação do teor de fluoreto nas folhas.

Foram utilizados dois tratamentos para o preparo dos chás: folhas não lavadas e folhas lavadas em água deionizada durante $5 \mathrm{~min}$ em imersão. Os chás foram preparados a partir da infusão de $5 \mathrm{~g}$ de folhas frescas, 
em $500 \mathrm{~mL}$ de água deionizada, a $100^{\circ} \mathrm{C}$ durante $5 \mathrm{~min}$. No segundo experimento, parte das folhas infundidas não lavadas, de cada espécie, foi infundida uma segunda vez durante 5 min em $500 \mathrm{~mL}$ de água a $100^{\circ} \mathrm{C}$ (Fung et al., 1999). No total, foram preparados 20 infusos de cada espécie, para o primeiro experimento, e 30 para o segundo.

O teor de fluoreto na matéria seca foi mensurado em folhas infundidas lavadas e não lavadas, e em folhas não infundidas. As amostras foliares foram secas em estufa, a $70^{\circ} \mathrm{C}$, e reduzidas, em moinho do tipo Wiley, a partículas com dimensões inferiores a $1 \mathrm{~mm}$. Posteriormente, alíquotas de $0,5 \mathrm{~g}$ de cada repetição foram submetidas à extração em ácido perclórico $0,1 \mathrm{M}$ (Garcia-Ciudad et al., 1985). Utilizou-se um ajustador de força iônica (Larsen \& Widdowson, 1971) para a determinação potenciométrica do teor de fluoreto. A quantidade de flúor presente no chá foi estimada por meio do cálculo da diferença entre o teor de flúor encontrado nas folhas não infundidas e o obtido para as folhas infundidas não lavadas. Os dados foram submetidos à análise de variância, empregando-se o Sistema de Análises Estatísticas e Genéticas (Euclydes, 1983) e as médias dos tratamentos foram comparadas pelo teste de Tukey, a 5\% de probabilidade.

Os danos foliares foram observados a partir do surgimento de lesões nas folhas, como cloroses e necroses, relatados em trabalhos com outras espécies em resposta ao flúor (Fornasiero, 2001; Sant'Anna-Santos et al., 2007; Pita-Barbosa et al., 2009). Para avaliação dos danos na micromorfologia foliar, amostras da lâmina foliar foram coletadas, fixadas em solução de Karnovsky (Karnovsky, 1965), desidratadas em série etílica e secas ao ponto crítico, em equipamento apropriado, modelo CPD 020 (Bal-Tec, Balzers, Liechtenstein). A superfície das folhas foi coberta com ouro, em metalizador modelo FDU010 (Bal-Tec, Balzers, Liechtenstein), e documentada em microscópio eletrônico de varredura com câmera digital acoplada modelo Leo 1430 VP (Zeiss, Cambridge, Inglaterra) do Núcleo de Microscopia e Microanálise da UFV.

\section{Resultados e Discussão}

$\mathrm{Na}$ análise visual das folhas de $P$. neochilus e de C. citratus, expostas ao poluente, não foi observada a ocorrência de cloroses ou necroses.
Ao microscópio eletrônico de varredura, observaram-se, em ambas as faces das folhas de P. neochilus, no tratamento controle, células epidérmicas com contorno sinuoso, junção celular do tipo sulcada (Figura 1 A), cutícula estriada, estômatos diacíticos (Figura 1 E) e numerosos tricomas tectores e glandulares capitados e peltados (Figuras 1 A e 2 A). Os tricomas capitados podem ter pedicelo curto unicelular e cabeça uni ou bicelular, ou pedicelo longo pluricelular com cabeça unicelular. Os tricomas peltados possuem pedicelo curto e cabeça ovoide formada por oito células. Os tricomas tectores são pluricelulares, unisseriados, com cutícula granulosa. Na porção basal, as células epidérmicas estão dispostas radialmente (Figura $2 \mathrm{C}$ ). Essa descrição coincide com o relatado por Duarte \& Lopes (2007) para a espécie.

Nas folhas de P. neochilus, expostas ao nevoeiro com flúor, constatou-se a modificação na forma e turgidez das células epidérmicas (Figura 1 B) e ruptura da cutícula (Figura $1 \mathrm{C}$ ). A célula apical dos tricomas secretores apresentou-se disforme (Figura 1 B e D), ao passo que, nos estômatos, houve alteração da turgidez celular e ruptura da crista estomática (Figura $1 \mathrm{~F}$ e G). Os tricomas tectores apresentaram-se flácidos e com dobras na parede celular da célula basal (Figuras 2 B, D e E). O grau de danos foi equivalente para as duas faces foliares, provavelmente por elas apresentarem características micromorfológicas semelhantes, como a presença de estômatos e tricomas abundantes. Azevedo (1995) constatou, em Glycine $\max$, que a base dos tricomas tectores constitui uma importante via de entrada para o flúor.

As folhas de C. citratus possuem epiderme com células poligonais e alongadas, ceras epicuticulares em forma de placas, estômatos paracíticos, pelos acúleos e micropelos (Figuras $3 \mathrm{~A}, \mathrm{C}$ e E), em ambas as faces da folha. Os estômatos e os micropelos são mais frequentes na face abaxial. Metcalfe (1960) relatou a presença de micropelos apenas na face abaxial. Os micropelos possuem, usualmente, célula basal mais larga e inflada que a célula distal e os pelos acúleos possuem base alargada e estão dispostos em fileiras longitudinais (Figura $3 \mathrm{~A}$ ).

Os principais danos ocasionados pelo flúor nas folhas de $C$. citratus foram lesão da crista estomática, obliteração do poro estomático por fragmentos de ceras (Figura 3 D e E), erosão das ceras epicuticulares (Figura 3 C) e ruptura da cutícula (Figura $3 \mathrm{~B}$ e E). 
A ocorrência de danos mais acentuados na face adaxial pode estar relacionada à maior densidade de tricomas e estômatos. Dados obtidos por Chaves et al. (2002) e Pita-Barbosa et al. (2009), em outras espécies de Poaceae, indicam que a base dos tricomas constitui uma via preferencial de entrada do flúor, em solução, nas folhas.
Para o teor de fluoreto, os dados obtidos no primeiro experimento, aos 20 dias $\left(10 \mu \mathrm{g} \mathrm{mL}^{-1}\right)$, seguiram a mesma tendência dos obtidos no segundo, aos 10 dias (20 $\mu \mathrm{g} \mathrm{mL}^{-1}$ ) (Tabela 1), conforme o esperado, uma vez que o acúmulo do poluente depende da interação entre a concentração de flúor e o tempo de exposição (Weinstein \& Davison, 2004). O teor de fluoreto acumulado na matéria seca de plantas expostas ao nevoeiro simulado

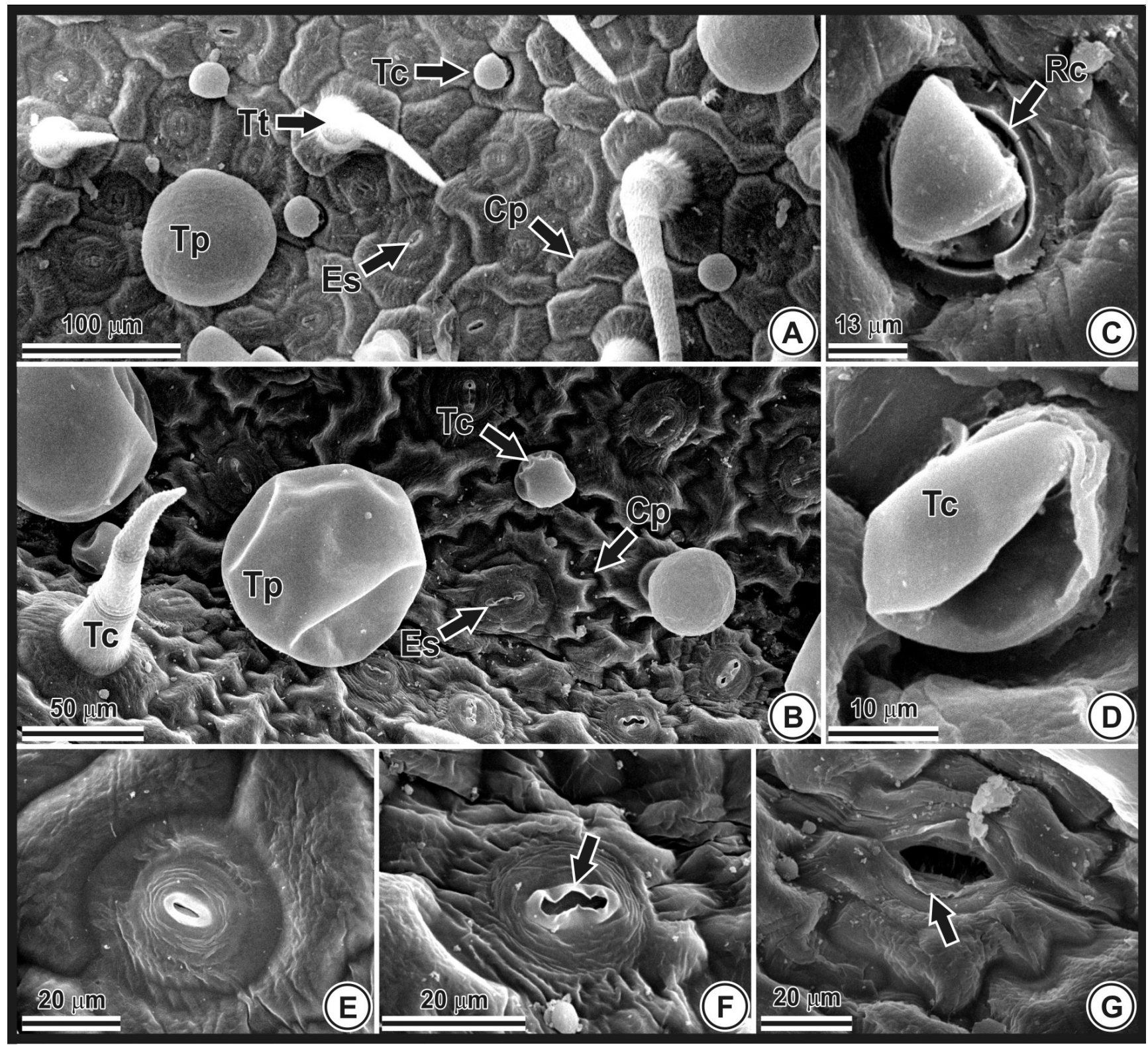

Figura 1. Micromorfologia foliar de Plectranthus neochilus. A e E, tratamentos controle; B, C, D, F e G, tratamentos com flúor $\left(10 \mu \mathrm{g} \mathrm{mL}^{-1}\right)$. A, epiderme adaxial: células epidérmicas com junção em sulcos, tricomas tectores (Tt), peltados (Tp) e capitados (Tc), e estômatos (Es); B, alteração no contorno das paredes anticlinais (Cp) e perda de turgidez das células epidérmicas; $\mathrm{C}$, ruptura da cutícula (Rc); D, tricoma capitado com célula apical disforme; E, estômato com forma e turgidez usuais; F, crista estomática deformada (seta); G, ruptura da crista estomática (seta). 
foi significativamente maior que o encontrado nas plantas do tratamento controle, para ambas as espécies, nos dois experimentos, tendo sido maior para $P$. neochilus. Entretanto, para C. citratus, o teor de fluoreto foi maior no segundo experimento, indicando que, nesta espécie, a exposição à dose mais elevada de flúor, mesmo que em menor tempo, favorece a maior retenção do poluente nas folhas (Azevedo, 1995). A quantidade de flúor acumulada pelas plantas varia conforme a espécie e o grau de exposição ao poluente, entre outros fatores (Treshow \& Anderson, 1991).

O maior teor de fluoreto encontrado em $P$. neochilus pode estar associado ao elevado grau de pilosidade das folhas. A junção celular sulcada pode também ter contribuído para o aumento da área de contato e retenção da solução por mais tempo sobre a folha, o que teria facilitado a absorção de flúor. Tuffi Santos et al. (2006) constataram, em folhas de Eucalyptus spp., que a formação de uma depressão na junção entre

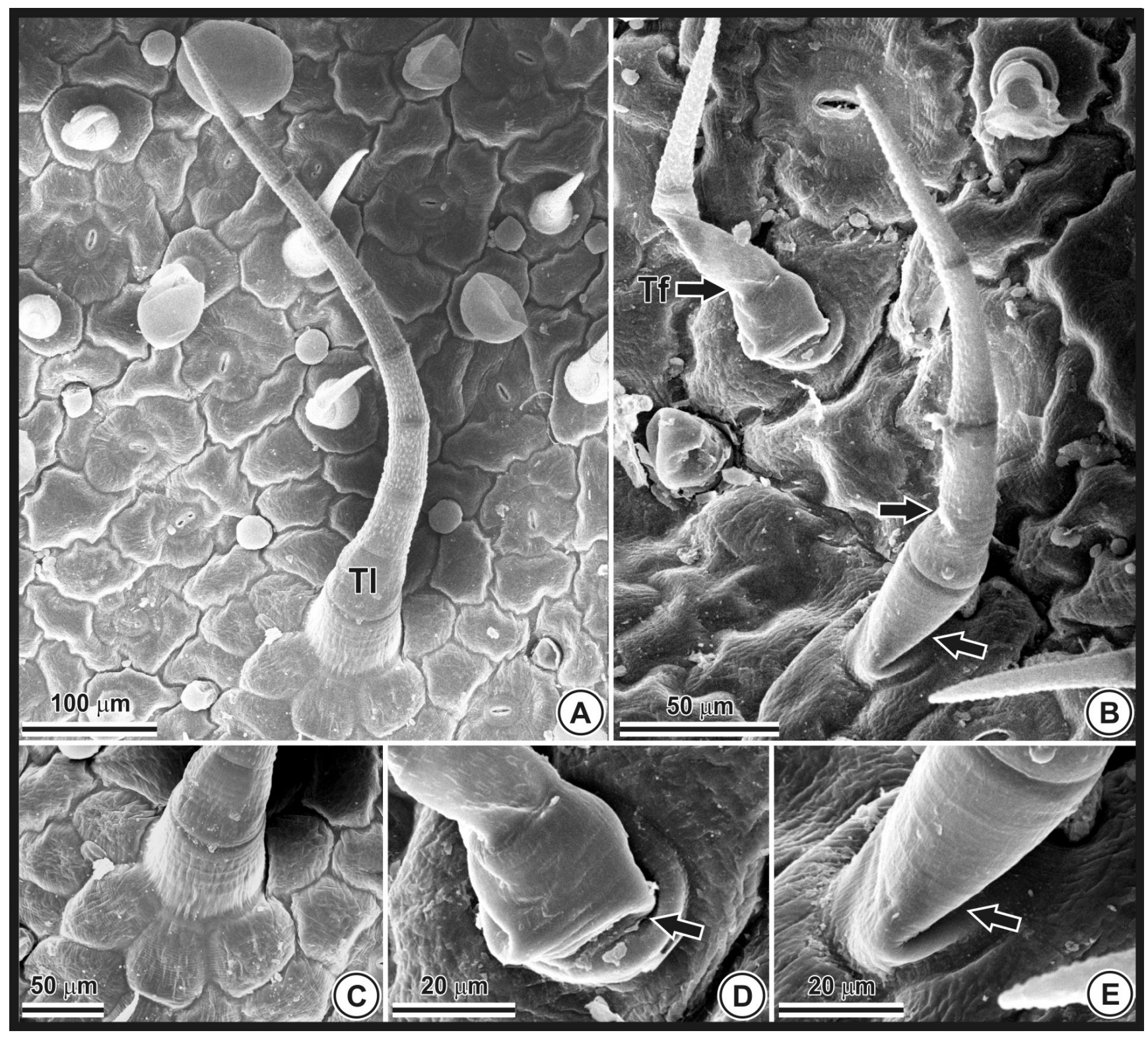

Figura 2. Micromorfologia foliar de Plectranthus neochilus. A e C, tratamento controle; B e D e E, tratamento com flúor (10 $\left.\mu \mathrm{g} \mathrm{mL}^{-1}\right)$. A, tricoma tector longo (Tl); B, tricoma longo com aspecto flácido (Tf) e dobras na parede (setas); C, células epidérmicas dispostas radialmente à base do tricoma; D e E, dobras na parede dos tricomas (setas). 
células epidérmicas favorece a retenção, hidratação e a absorção da solução contendo herbicida.

Não houve diferença significativa entre o teor de fluoreto de folhas infundidas não lavadas e de folhas infundidas lavadas para nenhuma das espécies (Tabela 1), evidenciando que a lavagem das folhas em água é um processo ineficiente para a remoção do flúor. O teor de fluoreto presente nas folhas infundidas pela segunda vez não diferiu estatisticamente do encontrado naquelas infundidas uma única vez, em contraposição aos resultados obtidos por Fung et al. (1999), que mostraram que $80-85 \%$ do total de fluoreto é liberado durante a infusão repetida e continuada das folhas de chá.

O percentual de flúor disponibilizado para a solução dos chás, após a infusão das folhas, foi estimado em $67 \%$ para C. citratus e $33 \%$ para as folhas de P. neochilus, no primeiro experimento, e 68 e $42 \%$, respectivamente, no segundo experimento. Fung et al. (1999) constataram,
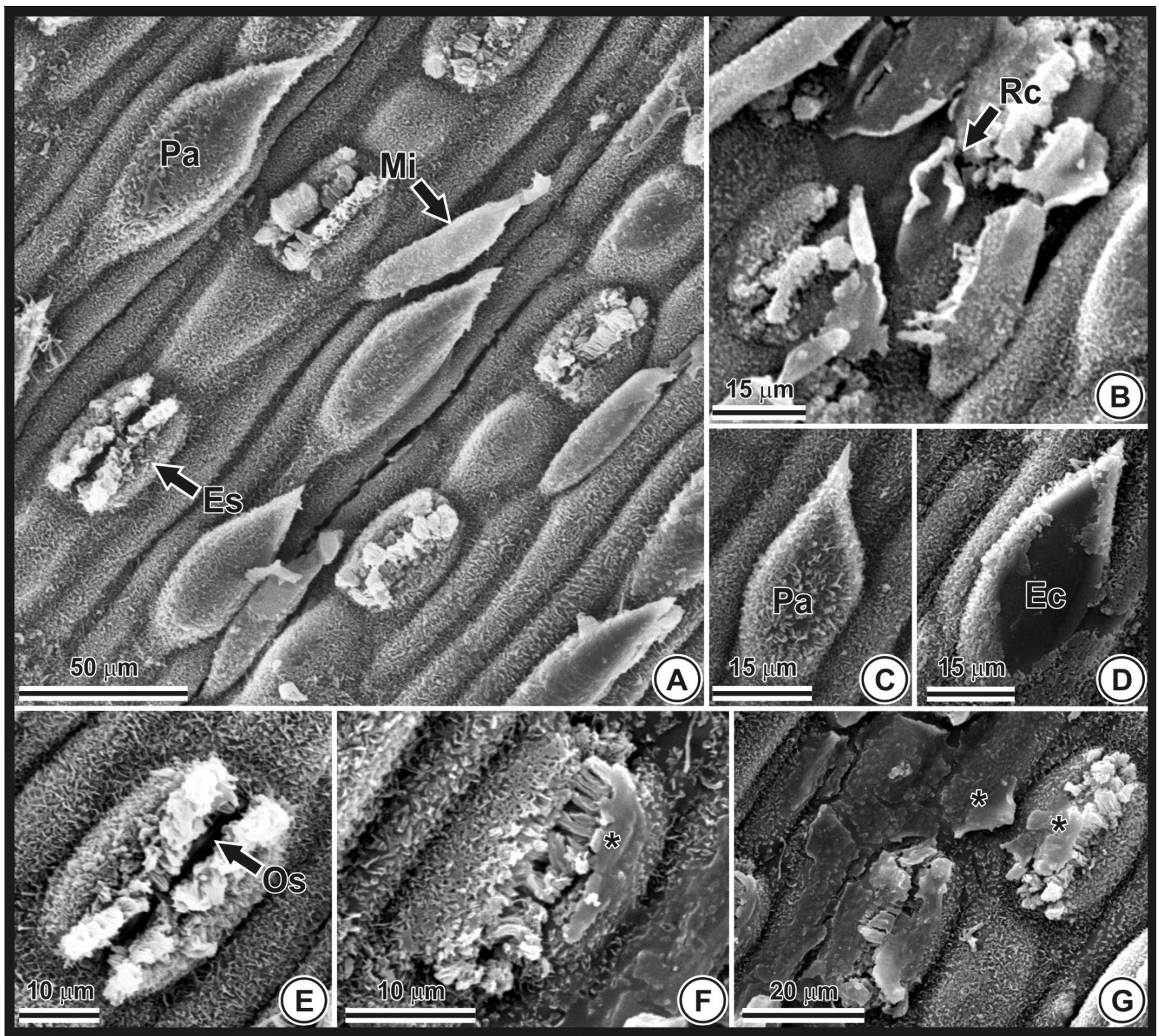

Figura 3. Micromorfologia da face abaxial da folha de Cymbopogon citratus. A, C e E, tratamento controle; B, D, F e G, tratamento com flúor (10 $\left.\mathrm{g} \mathrm{mL}^{-1}\right)$; A, pêlo acúleo $(\mathrm{Pa})$, micropêlo (Pi) e estômato (Es); B, ruptura da cutícula (Rc); C, detalhe do pêlo acúleo; D, erosão da cera epicuticular (Ec); E, detalhe do estômato evidenciando o ostíolo (Os); F e G, estômatos obliterados e cera epicuticular amorfa $(*)$. 
Tabela 1. Teor de fluoreto na matéria seca $\left(\mathrm{mg} \mathrm{g}^{-1}\right)$ de folhas de Cymbopogon citratus e Plectranthus neochilus do tratamento controle e o de plantas expostas ao flúor, em duas condições experimentais: $10 \mu \mathrm{g} \mathrm{mL}^{-1}$ de flúor durante 20 dias (experimento 1); e $20 \mu \mathrm{g} \mathrm{mL}^{-1}$ de flúor durante 10 dias (experimento 2) (1). $^{(1)}$.

\begin{tabular}{|c|c|c|c|c|}
\hline \multirow[t]{2}{*}{ Preparo } & \multicolumn{2}{|c|}{ Experimento 1} & \multicolumn{2}{|c|}{ Experimento 2} \\
\hline & C. citratus & P. neochilus & C. citratus & P. neochilus \\
\hline & \multicolumn{4}{|c|}{ Tratamento com flúor } \\
\hline Não infundida & $11,89 \pm 1,69 \mathrm{a}$ & $25,73 \pm 3,56 a$ & $16,36 \pm 0,87 \mathrm{a}$ & $25,89 \pm 6,05 \mathrm{a}$ \\
\hline Infundida não lavada & $4,02 \pm 1,45 b$ & $17,24 \pm 3,51 b$ & $5,20 \pm 0,46 b$ & $14,91 \pm 1,03 b$ \\
\hline Infundida lavada & $5,49 \pm 1,93 b$ & $16,59 \pm 2,85 b$ & $5,86 \pm 0,30 \mathrm{~b}$ & $11,55 \pm 2,66 b$ \\
\hline \multirow[t]{2}{*}{ Infundida não lavada 2} & $-(2)$ & - & $4,58 \pm 1,99 \mathrm{~b}$ & $12,29 \pm 3,75 b$ \\
\hline & \multicolumn{4}{|c|}{ Tratamento controle } \\
\hline Não infundida & $1,11 \pm 0,07 \mathrm{c}$ & $1,44 \pm 0,14 \mathrm{c}$ & $0,50 \pm 0,04 \mathrm{c}$ & $0,51 \pm 0,03 \mathrm{c}$ \\
\hline Infundida não lavada & $0,81 \pm 0,06 \mathrm{c}$ & $1,40 \pm 0,23 \mathrm{c}$ & $0,40 \pm 0,03 \mathrm{c}$ & $0,50 \pm 0,02 \mathrm{c}$ \\
\hline Infundida lavada & $0,72 \pm 0,04 \mathrm{c}$ & $1,54 \pm 0,17 \mathrm{c}$ & $0,48 \pm 0,03 \mathrm{c}$ & $0,53 \pm 0,02 \mathrm{c}$ \\
\hline Infundida não lavada 2 & - & - & $0,48 \pm 0,03 \mathrm{c}$ & $0,52 \pm 0,02 \mathrm{c}$ \\
\hline
\end{tabular}

${ }^{(1)}$ Médias \pm erro-padrão seguidas por letras iguais, nas colunas, não diferem pelo teste Tukey a $5 \%$ de probabilidade. ${ }^{(2)}$ Procedimentos não efetuados no experimento 1 .

em folhas de Camellia sinensis (L.) submetidas a 5 min de infusão, a liberação de $25-47 \%$ do fluoreto na solução de chás. A liberação mais acentuada de flúor na solução do chá de $C$. citratus sugere que a maior parte do poluente está adsorvido às ceras epicuticulares.

Apesar de os percentuais de liberação de flúor terem sido diferentes para as espécies, o teor do poluente presente na solução dos chás foi semelhante, sendo $7,87 \mathrm{mg} \mathrm{g}^{-1}$ para C. citratus e $8,49 \mathrm{mg} \mathrm{g}^{-1}$ para P. neochilus, no primeiro experimento, e $9,43 \mathrm{mg} \mathrm{g}^{-1} \mathrm{e}$ 9,83 no segundo experimento, respectivamente. Esses resultados indicam que o chá de ambas as espécies pode contribuir significativamente com a ingestão de flúor, dependendo do nível de consumo da bebida e das condições às quais as plantas estão expostas. A ingestão do chá de $P$. neochilus pode conferir menor risco à saúde, principalmente por tratar-se de tônico amargo de consumo geralmente esporádico. Maiores cuidados devem ser tomados na utilização de folhas de C. citratus, já que o seu chá é muito apreciado e geralmente consumido em maiores quantidades.

\section{Conclusões}

1. O elevado teor de fluoreto nas folhas de Cymbopogon citratus e Plectranthus neochilus e a ausência de sintomas visuais evidenciam que as espécies são tolerantes ao poluente.

2. A imersão das folhas em água, por $5 \mathrm{~min}$, antes do preparo do chá é ineficiente na remoção do flúor.
3. As espécies apresentam capacidade de acúmulo e de liberação diferenciadas, de acordo com suas características morfoanatômicas, no entanto, a quantidade de flúor liberada após a infusão das folhas é semelhante para as duas espécies.

\section{Referências}

AZEVEDO, A.A. Ação do flúor, em chuva simulada, sobre a estrutura foliar de Glycine $\max$ (L.) Merril. 1995. 95p. Tese (Doutorado) - Universidade de São Paulo, São Paulo.

CAO, J.; ZHAO, Y.; LIU, J.W.; XIRAO, R.; DANZENG, S.; DAJI, D.; YAN, Y. Brick tea fluoride as a main source of adult fluorosis. Food and Chemical Toxicology, v.41, p.535-542, 2003.

CHAVES, A.L.F.; SILVA, E.A.M. da; AZEVEDO, A.A.; CANO, M.A.O.; MATSUOKA, K. Ação do flúor dissolvido em chuva simulada sobre a estrutura foliar de Panicum maximum Jacq. (colonião) e Chloris gayana Kunth. (capim-Rhodes) - Poaceae. Acta Botanica Brasilica, v.16, p.395-406, 2002.

DUARTE, M. do R.; LOPES, J.F. Stem and leaf anatomy of Plectranthus neochilus Schltr., Lamiaceae. Revista Brasileira de Farmacognosia, v.17, p.549-556, 2007.

EUCLYDES, R.F. Manual de utilização do programa SAEG (Sistema para Análises Estatísticas e Genéticas). Viçosa: UFV, 1983. 59p.

EVANS, L.S.; GMUR, N.F.; COSTA, F. da. Leaf surface and histological perturbations of leaves of Phaseolus vulgaris and Helianthus annuus after exposure to simulated acid rain. American Journal of Botany, v.64, p.903-913, 1977.

FORNASIERO, R.B. Phytotoxic effects of fluorides. Plant Science, v.161, p.979-985, 2001. 
FUNG, K.F.; ZHANG, Z.Q.; WONG, J.W.C.; WONG, M.H. Fluoride contents in tea and soil from tea plantations and the release of fluoride into tea liquor during infusion. Environmental Pollution, v.104, p.197-205, 1999.

GARCIA-CIUDAD, A.; GARCIA-CRIADO, B.; EMETERIO, C.P. Determination of fluoride in plant samples by a potentiometric method and near-infrared reflectance spectroscopy. Communications in Soil Science and Plant Analysis, v.16, p.1107-1122, 1985.

HARINARAYAN, C.V.; KOCHUPILLAI, N.; MADHU, S.V.; GUPTA, N.; MEUNIER, P.J. Fluorotoxic metabolic bone disease: an osteo-renal syndrome caused by excess fluoride ingestion in the tropics. Bone, v.39, p.907-914, 2006.

HOAGLAND, D.R.; ARNON, D.I. The water culture method for growing plants without soil. California Agricultural Experiment Station, v.347, p.1-32, 1950.

KARNOVSKY, M.J. A formaldehyde-glutaraldehyde fixative of high osmolality for use in electron microscopy. Journal of Cell Biology, v.27, p.137-138, 1965.

KLUMPP, A.; DOMINGOS, M.; MORAES, R.M. de; KLUMPP, G. Effects of complex air pollution on tree species of the Atlantic Rain Forest near Cubatão, Brazil. Chemosphere, v.36, p.989-994, 1998.

LARSEN, S.; WIDDOWSON, A.E. Soil fluorine. Journal of Soil Science, v.22, p.210-221, 1971.

LIMA, C.B. de; BELLETTINI, N.M.T; SILVA, A.S. da; CHEIRUBIM, A.P.; JANANI, J.K.; VIEIRA, M.A.V.; AMADOR, T.S. Uso de plantas medicinais pela população da zona urbana de Bandeirantes-PR. Revista Brasileira de Biociências, v.5, p.600-602, 2007.

LORENZI, H.; MATOS, F.J.A. Plantas medicinais no Brasil: nativas e exóticas. Nova Odessa: Instituto Plantarum, 2002. 512p.

MARTINS, E.R.; CASTRO, D.M. de; CASTELLANI, D.C.; DIAS, J.E. Plantas medicinais. Viçosa: UFV, 2000. 220p.

METCALFE, C.R. Anatomy of the monocotyledons: I. Gramineae. Oxford: Clarendon, 1960. 731p.

PILLA, M.A.C.; AMOROZO, M.C. de M.; FURLAN, A. Obtenção e uso das plantas medicinais no distrito de Martim Francisco, Município de Mogi-Mirim, SP, Brasil. Acta Botanica Brasilica, v.20, p.789-802, 2006.
PITA-BARBOSA, A.; SANT'ANNA-SANTOS, B.F.; SILVA, K.L.F.; AZEVEDO, A.A.; ROCHA, D.I. Efeitos fitotóxicos do fluoreto na morfoanatomia foliar de Brachiaria brizantha (Hochst. Ex A. Rich.) Stapf e Brachiaria decumbens Stapf (Poaceae). Acta Botanica Brasilica, v.23, p.1027-1033, 2009.

SANT'ANNA-SANTOS, B.F.; DUQUE-BRASIL, R.; AZEVEDO, A.A.; SILVEIRA, A. de S.; ARAÚJO, J.M. de; AGUIAR, R. Utilização de parâmetros morfoanatômicos na análise da fitotoxidez do flúor em folhas de Magnolia ovata (A. St.-Hil.) Spreng. (Magnoliaceae). Revista Árvore, v.31, p.761-771, 2007.

TAUFNER, C.F.; FERRAÇO, E.B.; RIBEIRO, L.F. Uso de plantas medicinais como alternativa fitoterápica nas unidades de saúde pública de Santa Teresa e Marilândia, ES. Natureza On Line, v.4, p.30-39, 2006.

TRESHOW, M.; ANDERSON, F.K. Plant stress and air pollution. New York: John Willey \& Sons, 1991. 283p.

TUFFI SANTOS, L.D.; IAREMA, L.; THADEO, M.; FERREIRA, F.A.; MEIRA, R.M.S.A. Características da epiderme foliar de eucalipto e seu envolvimento com a tolerância ao glyphosate. Planta Daninha, v.24, p.513-520, 2006.

WEINSTEIN, L.H.; DAVISON, A. Fluorides in the nvironment: effects on plants and animals. Oxford: CABI Publishing, 2004. $287 \mathrm{p}$.

WONG, M.H.; FUNG, K.F.; CARR, H.P. Aluminium and fluoride contents of tea, with emphasis on brick tea and their health implications. Toxicology Letters, v.137, p.111-120, 2003.

WORLD HEALTH ORGANIZATION. Fluorides. Geneva: WHO, 2002. 268p. (Environmental Health Criteria, 227)

XIONG, X.Z.; LIU, J.L.; HE, W.H.; XIA, T.; HE, P.; CHEN, X.M.; YANG, K.D.; WANG, A.G. Dose effect relationship between drinking water fluoride levels and damage to liver and kidney functions in children. Environmental Research, v.103, p.112-116, 2007.

YI, J.; CAO, J. Tea and fluorosis. Journal of Fluorine Chemistry, v.129, p.76-81, 2008.

ZARONI, M.; PONTAROLO, R.; ABRAHÃO, W.S.M.; FÁVERO, M.L.D.; CORREA JÚNIOR, C.; STREMEL, D.P. Qualidade microbiológica das plantas medicinais produzidas no Estado do Paraná. Revista Brasileira de Farmacognosia, v.14, p.29-39, 2004. 